\title{
Laryngeal Ligament
}

National Cancer Institute

\section{Source}

National Cancer Institute. Laryngeal Ligament. NCI Thesaurus. Code C32933.

Any of the ligaments associated with the larynx. 